\title{
Comparison of Short and Longer Term Loading on the Creep Behaviour of Alumina-Silicon Carbide Whisker Composites
}

\author{
H. Swan, ${ }^{+}$A.R. de Arellano-Lopez, ${ }^{++}$A. Dominguez-Rodriguez, ${ }^{++}$ \\ J. L. Routbort, $\ddagger$ and M. V. Swain ${ }^{\ddagger \ddagger}$ \\ ${ }^{+}$Dept. of Physics, Chalmers University of Technology, Goteborg, Sweden \\ ${ }^{++}$Dept. de Fisica de la Materia Condensada, Universidad de Sevilla, Sevilla, Spain

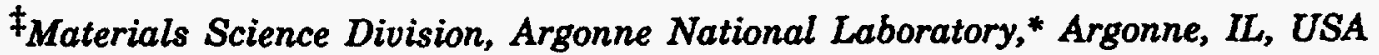 \\ ${ }^{\ddagger}$ Dept. of Mechanical Engineering, University of Sydney, Sydney, NSW, Australia
}

November 1992

The subritted manuscript has been authored by a
contractior of the U.S. Govemment under contract No.
W-31-109-ENG-38. Accordingly, the U.S. Government
retains a nonexclusive, royatty-free lcense to publish or
reproduce the publinhed torm of this contrbution, or allow
others to do so br US. Govemment purposes.

athers to do so, for U.S. Government purposes.

\section{DISCLAIMER}

\begin{abstract}
This report was prepared as an account of work sponsored by an agency of the United States Government. Neither the United States Government nor any agency thereof, nor any of their employees, makes any warranty, express or implied, or assumes any legal liability or responsibility for the accuracy, completeness, or usefulness of any information, apparatus, product, or process disclosed, or represents that its use would not infringe privately owned rights. Reference herein to any specific commercial product, process, or service by trade name, trademark, manufacturer, or otherwise does not necessarily constitute or imply its endorsement, recommendation, or favoring by the United States Government or any agency thereof. The views and opinions of authors expressed herein do not necessarily state or reflect those of the United States Government or any agency thereof.
\end{abstract}

Submitted to Journal of the Australian Ceramic Society. ${ }^{\text {*Work supported }}$ by the U.S. Department of Energy, BES-Materials Sciences,
under contract \#W-31-109-ENG-38. 


\section{DISCLAIMER}

Portions of this document may be illegible in electronic image products. Images are produced from the best available original document. 


\title{
COMPARISON OF SHORT AND LONGER TERM LOADING ON THE CREEP BEHAVIOUR OF ALUMINA-SILICON CARBIDE WHISKER COMPOSITES
}

\author{
A. H. SWAN, A. R. de ARELLANO-LOPEZ*, A. DOMINGUEZ-RODRIGUEZ*, J. L. \\ ROUTBORT $^{+}$AND M. V. SWAIN"
}

Department of Physics, Chalmers University of Technology, S-412 96 Göteborg, Sweden

*Departamento de Fisica de la Materia Condensada, Universidad de Sevilla, Sevilla, Spain

${ }^{+}$Materials Science Division, Argonne National Laboratory, Argonne, Illinois 60439, USA

\#Department of Mechanical Engineering, University of Sydney, Sydney, NSW 2006, Australia

\section{INTRODUCTION}

The incorporation of $\mathrm{SiC}$ whiskers into alumina ceramics has resulted in several improved room temperature properties of the composite such as fracture toughness [1], strength [1], erosion resistance [2] and fatigue [3]. The creep resistance has also been generally observed to increase with the addition of whiskers [4-11]. However, significant scatter in measured secondary creep rates still exist, depending on the material and the test conditions that were utilized.

The objective of this investigation was to compare two separate creep tests performed in compression using a $\mathrm{SiC}_{\mathrm{W}} / \mathrm{Al}_{2} \mathrm{O}_{3}$ material obtained from the same process batch. The differences in creep behaviour between the tests could thus be ascribed to the difference in creep conditions solely. In one case the creep behaviour was studied under short term loading $(<3 \mathrm{~h})$ conditions in air, while longer term loading $(<100 \mathrm{~h})$ conditions in argon were applied in the other case. The creep results and the microstructure of the samples were compared and related to each other, and to previous results in the literature. 


\section{EXPERIMENTAL}

A commercially available $\mathrm{SiC}_{\mathrm{W}} / \mathrm{Al}_{2} \mathrm{O}_{3}$ material ${ }^{*}$ was used in all tests. This is a typical hot pressed $\mathrm{SiC}_{\mathrm{W}} / \mathrm{Al}_{2} \mathrm{O}_{3}$ material containing $30 \mathrm{vol} \% \mathrm{SiC}$ whiskers. The alumina grain size was observed to be 1-2 $\mu \mathrm{m}$ and the whiskers had a diameter of $0.1-1 \mu \mathrm{m}$ and lengths typically between $1-10 \mu \mathrm{m}$. Microstructural studies showed that the amount of interfacial glassy phase was very small, present only as thin films along the whisker/matrix grain boundaries and at some $\mathrm{Al}_{2} \mathrm{O}_{3} / \mathrm{Al}_{2} \mathrm{O}_{3}$ grain boundaries.

For the short term creep (STC) tests, cylindrical specimens with a length to diameter ratio of $\sim 2: 1$ were tested in compression using an Instron servo-hydraulic testing machine (model 1343). The specimens were slowly heated in air to the test temperature and then kept at this temperature for 45 minutes before the load was applied. Compressive creep stresses ranging from $25 \mathrm{MPa}$ to $200 \mathrm{MPa}$ were used. When reasonably steady state creep conditions had been obtained, the load was held constant for another 30 minutes before being increased. These test times can be considered short when compared to conventional creep testing. After testing, the specimens were cooled down under a stress of $200 \mathrm{MPa}$. Creep tests were performed at temperatures between $1200^{\circ} \mathrm{C}$ and $1350^{\circ} \mathrm{C}$, with a new specimen being used for each temperature. The stress exponent and activation energies were determined. SEM and TEM samples of the deformed specimens were prepared and studied. A more detailed description of the creep test has been published earlier [11].

For the longer term creep (LTC) tests, samples approximately $3 \mathrm{~mm} \times 3 \mathrm{~mm} \times 6 \mathrm{~mm}$ were cut and deformed at $1400^{\circ} \mathrm{C}$ in argon using a constant load creep apparatus [12]. Two specimens were tested at different conditions. LTC specimen 1 was deformed $2 \%$ using a constant stress of $79 \mathrm{MPa}$. LTC specimen 2 was deformed a total of $10 \%$ using stresses ranging from $73 \mathrm{MPa}$ to $92 \mathrm{MPa}$. The stress exponent could thus be determined in this case. The specimens were cooled down under stress after the creep test. SEM and TEM specimens were prepared and studied for both specimens.

\section{RESULTS}

For the short term creep (STC), the relationship between creep rate and applied stress is shown in Fig. 1. No bimodal creep behaviour was observed and the stress exponent, $n$, was found to be $\sim 1.5$. The activation energy, $Q$, was found to be $370 \pm 50$ $\mathrm{kJ} / \mathrm{mol}$. These results differ somewhat from the longer term creep (LTC) results. Specimen 2 exhibited a bimodal creep behaviour with a stress exponent of $\sim 1$ at lower stresses, increasing to $\sim 5$ for the highest stress used (92 MPa). LTC specimen 1 was thus crept at a stress level below the threshold stress. The two specimens then represents different creep regions which were subsequently studied by SEM/TEM.

\footnotetext{
* ACMC, Greer, South Carolina
} 


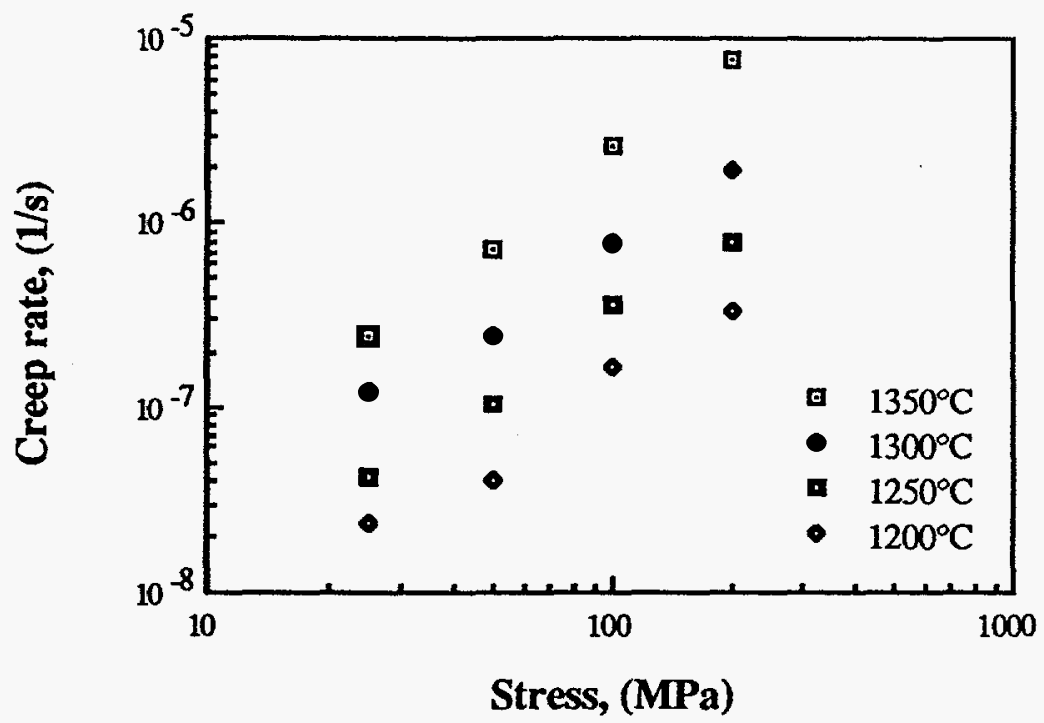

Figure 1. Strain rate vs stress diagram for short term creep (STC) specimens with whiskers parallel to the load direction. The stress exponent, $n$, was found to vary between 1.4 and 1.7.

The strain rate was also compared for the two creep tests. However a direct comparison could not be made as the temperature and environment were different for the tests. The measured long term creep rate was adjusted for the difference in temperature using $\mathrm{Q}=370 \mathrm{~kJ} / \mathrm{mol}$. The thus adjusted LTC rate was roughly an order of magnitude slower than the short term creep rate. Note however that the difference is strongly affected by the value of $Q$, which should be considered uncertain. Since the same material was used for both tests, the difference in creep rate must be due to either (1) the duration of the creep tests; (2) the argon vs air environment; or (3) the different specimen geometry and apparatus.

The different specimen geometry and apparatus should not cause any difference in measured creep rate, but the environmental difference has been shown to affect the composite creep rate $[9,10]$. The creep rate has been observed to increase by a factor of $\sim 3$ to 5 [10] in air as compared to an inert environment. The remaining difference should thus be due to the different duration of the creep tests.

Microstructural studies of the STC material showed that extensive intergranular cavitation had occurred as a result of grain boundary sliding, Fig. 2 (a). Oxidation of the $\mathrm{SiC}$ whiskers was observed in air. This resulted in the formation of an aluminosilicate glassy phase along the interface, as shown in Fig. 2 (b). This glassy phase was sometimes found to spread intergranularly into the matrix immediately surrounding the whisker.

The microstructural appearance of the longer term creep specimens are different from each other as well as to the STC specimens. The LTC specimen 1, tested at 72 $\mathrm{MPa}$ ( $\mathrm{n}=1$ regime), had the same general appearance as the as-received specimen, however extensive strain contrast, especially at multi-grain junctions and around 
whiskers was observed. Very little cavitation was observed as shown in Fig. 3 (a). As expected, no oxidation was observed, and the interface film thickness remained unchanged. The LTC specimen 2, tested at stresses up to $92 \mathrm{MPa}$ ( $n \sim 5$ regime), showed extensive crack-like cavitation, preferentially along the whisker interfaces, Fig. 3 (b). The cavities occasionally interlinked to form longer microcracks. An increased extent of strain contrast was observed, as for LTC specimen 1 (Fig. 4).

No oxidation was observed in the material tested in argon environment and the thickness of the whisker/matrix interface film remained the same during the test. The LTC results indicate the importance of cavitation in the deformation process at the higher stress. However it must be remembered that specimen 2 was deformed $10 \%$ while specimen 1 only was deformed $2 \%$. No increased dislocation density was observed in any of the specimens.
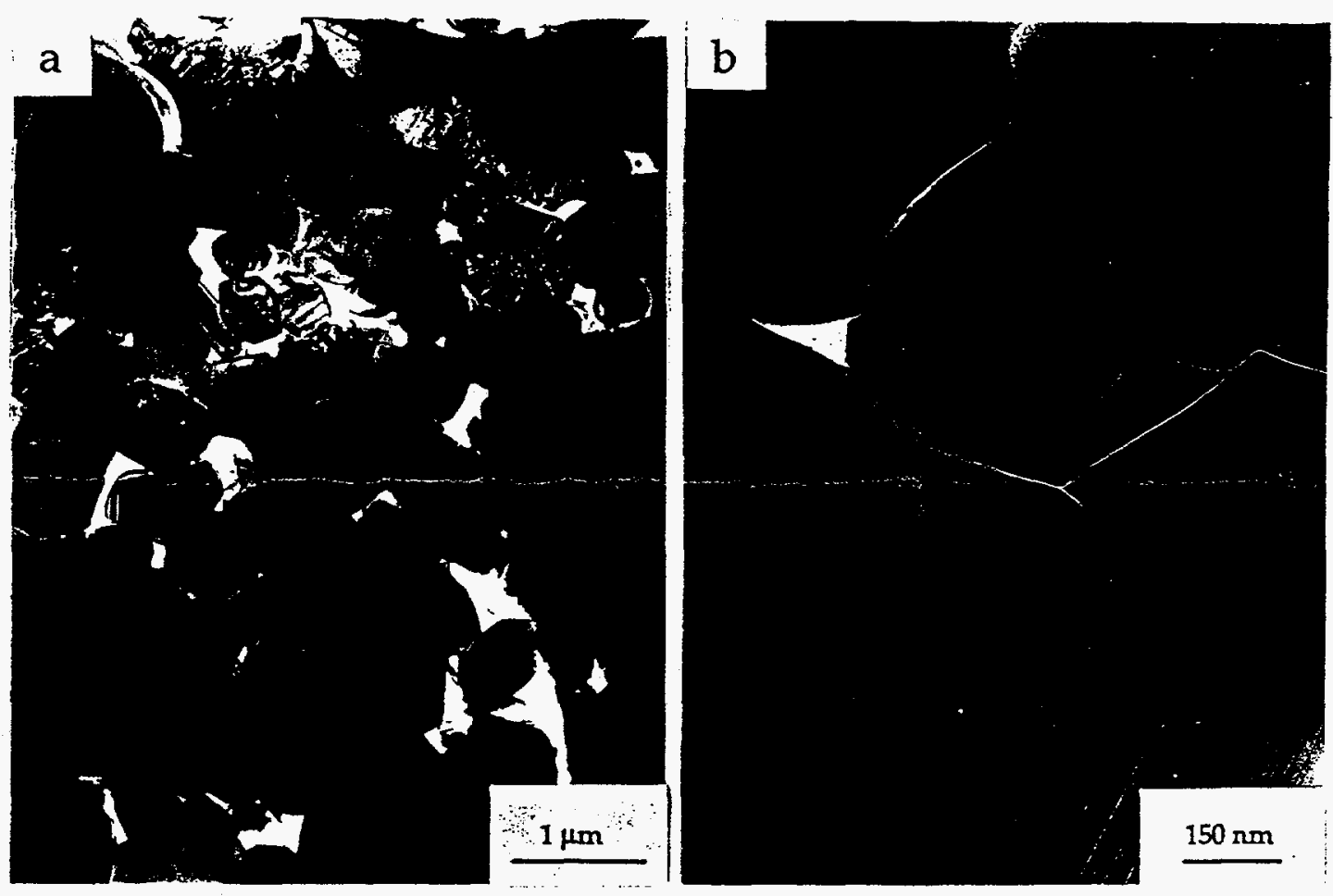

Figure 2. TEM micrographs of a short term creep (STC) specimen showing (a) extensive cavitation that occurred during creep, and (b) whisker oxidation, resulting in the formation of a glassy phase which was found to spread intergranularly through the matrix. 


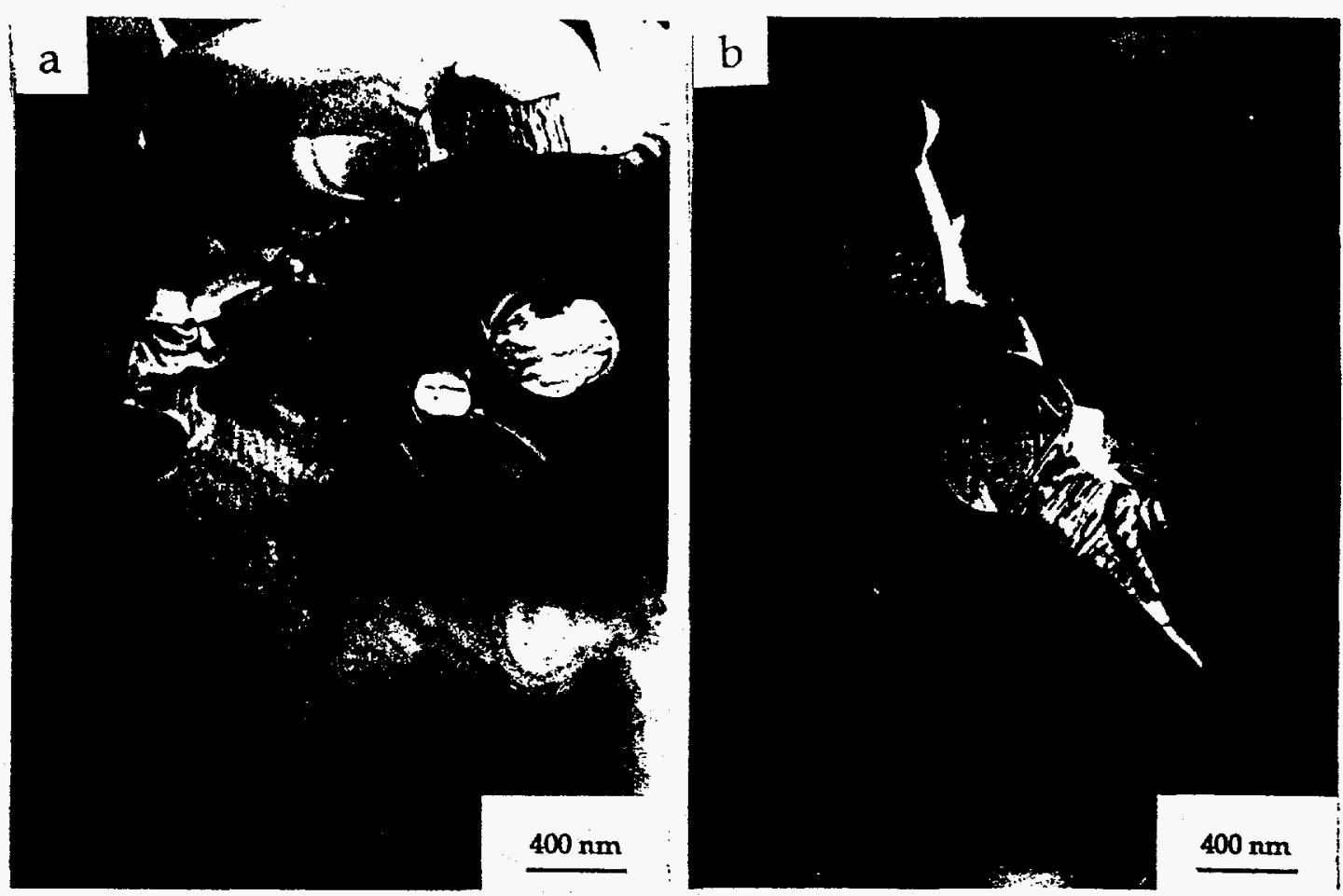

Figure 3. TEM micrographs showing the microstructure of the longer term creep (LTC) specimens. (a) LTC specimen 1 , tested at $72 \mathrm{MPA}$ which is below the cavitation threshold stress, showing an increased strain contrast, but minimal cavitation. (b) LTC specimen 2, tested at stresses up to $92 \mathrm{MPa}$ ( $n \sim 5$ regime), showed extensive crack-like cavitation, preferentially along the whisker interfaces.

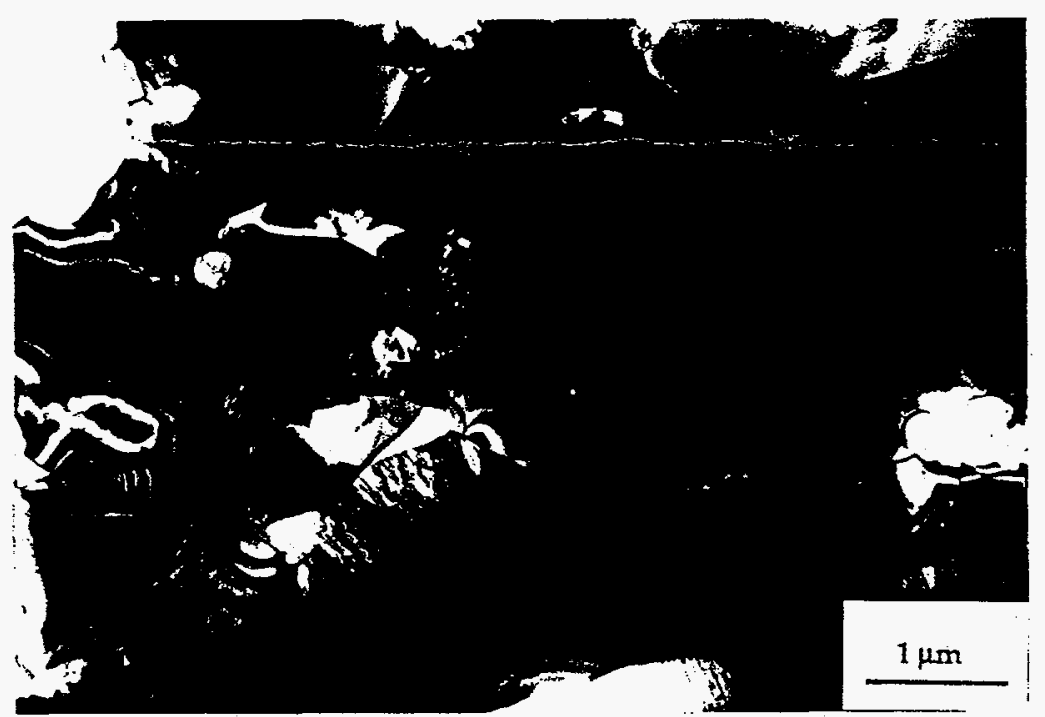

Figure 4. TEM micrograph of the longer term creep (LTC) specimen 2, showing cavitation and strain contrast. Virtually no glassy films could be observed at the matrix interfaces.

\section{CONCLUDING DISCUSSION}

Two main differences were observed between the short term and long term creep tests, i.e. the measured creep rates and the stress dependencies of the creep rate. Bimodal creep behaviour was observed for the LTC specimen at $1400^{\circ} \mathrm{C}$ while no indication of bimodal creep was observed for the STC specimens at $1200^{\circ} \mathrm{C}-1350^{\circ} \mathrm{C}$. 
The difference in creep rate ( $\sim 10$ fold increase in STC compared to LTC) could largely be accounted for by the difference in environment. A change from inert to air environment has been shown to increase the strain rate by a factor of 3-5 [10] depending on the temperature. The remaining difference of a factor $\sim 2-3$ can thus be ascribed to the difference in duration of the creep tests. An extended STC test did in fact show a slow decrease in strain rate with time, stabilizing at a value a factor $\sim 2$ lower than the measured strain rate after 1 hour [11]. In light of the above, the measured strain rates can be considered reasonably consistent. The rate obtained in argon agreed within a factor of 1.5 with earlier creep results obtained using ARCO material.

The difference in measured stress exponents for STC $(\sim 1.5)$ and LTC $(1$ and $\sim 5)$ is more difficult to account for. The different creep behaviour must be accounted to either the difference in temperature $\left(1200-1350^{\circ} \mathrm{C}\right.$ vs $\left.1400^{\circ} \mathrm{C}\right)$ or the difference in environment (air vs argon), or both. A similar study by Lipetzky et al. [10] in air and nitrogen at temperatures between $1200^{\circ} \mathrm{C}$ and $1400^{\circ} \mathrm{C}$ exhibited similar qualitative behaviour. A bimodal behaviour was observed in the inert nitrogen environment at $1400^{\circ} \mathrm{C}$, however this was not observed for the specimen tested in air. Furthermore, there was no indication of a bilinear response at lower temperatures in the nitrogen environment [10]. However the stress exponent remained high $(\sim 3)$ in those cases. The main reason for this difference must be due to the environment. The presence of air causes the whiskers to oxidate which results in the formation of an aluminosilicate glassy phase, spreading intergranularly from the whisker/matrix interfaces into the matrix. This glassy phase facilitates grain boundary sliding, grain boundary diffusion and cavitation. The critical stress for cavitation controlled creep would thus be lowered, which is in agreement with reported observations [13]. Furthermore the threshold stress for cavitation may not only be lowered, but its influence on the creep parameters $(n, Q)$ reduced, as the glassy phase controls the cavitation process.

For the LTC specimens tested in argon, no glassy phase is formed. The transition from diffusion accommodated grain boundary sliding to cavitation (nonaccommodated grain boundary sliding) occurs at a specific stress level, dependent upon the temperature. Deformation occurs by non-accommodated grain boundary sliding at lower temperatures, but when the temperature is sufficiently high, a ratecontrolling accommodation can occur by a diffusion mechanism at low stresses. This would give rise to the observed bimodal creep behaviour. Non-accommodated grain boundary sliding might possibly still take place at these low stresses, however to a much smaller extent, and without being rate-determining. The TEM studies of the two LTC specimens were in support of the hypothesis above. Specimen 1, tested below the threshold stress level did not contain an increased level of porosity, whereas this was the case for the other specimen tested at stresses above the threshold stress (Fig. 3). The hypothesis must however be further tested.

The strain rate was generally found to decrease in the whisker reinforced alumina as compared to non-reinforced alumina. The whiskers effectively slow down the rate of deformation. This is believed to be due to the more extensive shape changes required 
for the alumina grains in order to accommodate the grain boundary sliding in the presence of the rigid $\mathrm{SiC}$ whiskers. This belief has become widely accepted in recent years [8-11], however the details of the actual deformation process, e.g. how the stresses are transferred from the matrix to the whiskers, etc., is still unknown.

\section{CONCLUSIONS}

- The environment and the duration of the creep test strongly influence the measured creep rate. The measured STC and LTC creep rates were in good agreement when the difference in environment and duration was accounted for.

- The whiskers were found to slow down the rate of deformation. This was due to the more extensive shape changes required for the alumina grains in order to accommodate the grain boundary sliding in the presence of the rigid whiskers.

- The air environment affects the deformation process and changes the measured creep parameters. This is due to oxidation of the whiskers, resulting in the formation of an intergranular glassy phase.

- In the inert argon environment a change from diffusion to cavitation creep was observed at $1400^{\circ} \mathrm{C}$ at a threshold stress of $\sim 90 \mathrm{MPa}$. This effect was not observed in air as the glassy phase facilitates grain boundary sliding and cavitation.

\section{ACKNOWLEDGEMENTS}

Dr Bill Sinclair of BHP Melbourne Research Laboratories is thanked for supplying the material. H Swan would like to acknowledge the Swedish Institute for the financial support.

\section{REFERENCES}

1. Becher, P. F. and Wei, G. C., "Toughening behaviour in SiC-Whisker-Reinforced Alumina", C. Am. Ceram. Soc., (1984), 12, 67, C-267-C-269.

2. Sykes, M. T., Scattergood, R. O. and Routbort, J. L., "Erosion of SiC-Reinforced Alumina Ceramic Matrix Composites", Composites, (1987), 2, 18, 153-163.

3. Han, L. X. and Suresh, S., "High-Temperature Failure of an Alumina-Silicon Carbide Composite under Cyclic Loads: Mechanisms of Fatigue Crack Tip Damage", J. Am. Ceram. Soc., (1989), 7, 72, 1233-1238.

4. Chokshi, A. H. and Porter, J. R., "Creep Deformation of an Alumina Matrix Composite Reinforced with Silicon Carbide Whiskers", C. Am. Ceram. Soc., (1985), 6, 68, C-144-C-145.

5. Xia, K. and Langdon, T. G., "The Mechanical Properties at High Temperatures of $\mathrm{SiC}$ Whisker-Reinforced Alumina", in High Temperature/High Performance Ceramics, ed. by F.D. Lemkey, S.F. Fishman, A.G. Evans and J.R. Strife, (Materials Research Society, Pittsburgh, PA, 1988), 120, 265 - 270. 
6. Liu, D. S. and Majidi, A. P., "Creep Behavior of $\mathrm{SiC}_{\mathrm{w}} / \mathrm{Al}_{2} \mathrm{O}_{3}$ Composites", in Ceramic Materials \& Components for Engines, (American Ceramic Society, Westerville, OH, 1989), 958 - 967.

7. Lipetzky, P., Nutt, S. R. and Becher, P. F., "Creep Behavior of an $\mathrm{Al} 2 \mathrm{O} 3$ - SiC Composite", in High Temperature/High Performance Ceramics, ed. by F.D. Lemkey, S.F. Fishman, A.G. Evans and J.R. Strife, (Materials Research Society, Pittsburgh, 1988), 120, 271 - 277.

8. Lin H, T. and Becher, P. F., "Creep Behavior of a SiC-Whisker-Reinforced Alumina", J. Am. Ceram. Soc., (1990), 5, 73, 1378-1381.

9. Arellano-López, A. R., Cumbrera, F. L., Domínguez-Rodríguez, A., Goretta, K. C. and Routbort, J. L., "Compressive Creep of SiC-Whisker-Reinforced Al2O3", J. Am. Ceram. Soc., (1990), 5, 73, 1297-1300.

10. Lipetzky, P., Nutt, S. R., Koester, D. A. and Davis, R. F., "Atmospheric Effects on Compressive Creep of SiC-Whisker-Reinforced Alumina", J. Am. Ceram. Soc., (1991), 6, 74, 1240-1247.

11. Swan, A. H., Swain, M. V. and Dunlop, G. L., "Compressive Creep of SiC Whisker Reinforced Alumina", J. Eur. Cer. Soc, in press.

12. Gervais, H., Pellesier, B. and Castaing, J., "Apparatus for the Measurement of High-Temperature Compressive Creep of Ceramics (in Fr.)", Rev. Int. Hautes Temp. Refract., (1978), 15, 43-47.

13. de Arellano-López, A. R., in Ph. D. Thesis, (University of Sevilla, 1991). 